\title{
Preventing risks from illegal online gambling using effective legal design on landing pages
}

\author{
María José Schmidt-Kessen*, Julia Hörnle ${ }^{\circ}$, Alan Littler ${ }^{\dagger}$ \\ * Assistant Professor, Copenhagen Business School \\ 'Professor in Internet Law, Queen Mary University London \\ ${ }^{\dagger}$ Gaming Lawyer, Kalff Katz \& Franssen
}

\begin{abstract}
Gambling regulators in several European jurisdictions use website blocking as enforcement tool against illegal online gambling websites. Users trying to access blocked gambling websites are redirected to a landing page provided by the regulator. We analyse how insights from legal design could improve the effectiveness of landing pages as communication channel between regulators and players.
\end{abstract}

Keywords: online gambling, regulation, website blocking, legal design

\section{Introduction}

Gambling regulators in Europe use a variety of tools for making it more difficult for illegal online gambling websites to offer their services to players. One of these tools is the use of website blocking. When users try to access a blocked gambling site, they are redirected to a landing page set up by the regulator that informs them about the illegality of the online gambling offer they are trying to access. Despite the fact that website blocks can be easily circumvented, gambling regulators find that the landing page has a very important warning function, since many players are not aware whether or not a certain online gambling website is illegal, and often do not understand the risks that are involved when playing on illegal sites. ${ }^{1}$ The landing page thus acts as an important communication tool between regulators and players, and informs players about the law.

Given that the landing page is the most important tool that regulators have at hand to inform users about the illegality of a certain gambling website, it should be designed in the most effective way to convey this information to the user and influence user behaviour in the desired way, i.e. channelling demand to legal ${ }^{2}$ gambling offers.

Insights from legal design patterns (Haapio and Hagan, 2016), could be useful to draw up best practice guidelines for landing page design from which all gambling regulators could benefit. The optimization of how to most effectively convey legal information and induce users to engage in the behaviour that a regulatory framework intends to achieve has been

\footnotetext{
${ }^{1}$ We also discuss and explain the use of website blocking and landing pages in Julia Hörnle; Alan Littler; Gareth Tyson; Eranjan Padumadasa; Maria Jose Schmidt-Kessen; Damilola Isaac Ibosiola, Evaluation of Regulatory Tools for Enforcing Online Gambling Rules and Channelling Demand towards Controlled Offers, Luxembourg : Publications Office of the European Union 2018, available at https://publications.europa.eu/en/publication-detail//publication/6bac835f-2442-11e9-8d04-01aa75ed71a1/language-en. The research is based on surveys and interviews with 24 European gambling regulators and around 20 other stakeholders from the gambling industry. The research underlying the Report was funded by the European Commission.

${ }^{2}$ When we use the term "legal offers" we refer to those offers that are have obtained a local license.
} 
conducted by lawyers and information designers in other contexts already, e.g. in the area of contracts or privacy notices. We suggest to tap into the expertise and experience of already existing projects on effective legal design and apply these insights to landing pages.

The article starts with explaining the regulatory context in which landing pages are used. It then presents a number of examples of landing pages used by various European gambling regulators. Lastly, it reflects upon how insights from legal design on privacy notices and behavioural research could be conducted to improve the legal design of landing pages.

\section{Online Gambling Regulation}

Online gambling is a rapidly growing industry. The size of the global online gambling market was estimated at 45.8 Million US dollars in 2017, and is predicted to double in size by $2024 .{ }^{3}$ In the UK it has been reported that online gambling has not only grown exponentially, but that the losses of gamblers have almost doubled in 2018, compared to 2008. UK gamblers have lost in aggregate a record $£ 14.5$ billion in $2018 .{ }^{4}$

Online gambling is regulated in many jurisdictions around the world, but regulatory approaches vary widely (Hörnle \& Zammit 2010; Gainsbury et al., 2013). While online gambling is prohibited in some jurisdictions, e.g. in the US and Turkey, other states control it tightly. In Finland, for example, online gambling can be offered only by a state-owned monopolist. Yet other jurisdictions have chosen to open up online gambling markets to private operators that need to obtain a license in order to operate gambling websites legally, particularly for sports betting. ${ }^{5}$ In Europe, this has been the case in a majority of European Union Member States, including, for example, the United Kingdom, Denmark, Italy, Spain, and the Czech Republic. In these jurisdictions, the provision of locally unlicensed online gambling is generally considered illegal by criminal or administrative law. While gambling regulators are thus tasked with monitoring licensed operators and their conformity with gambling regulation, they also have to deal with combatting illegal online gambling, frequently provided by operators offshore, ${ }^{6}$ from outside the jurisdiction.

Online gambling is not just a simple interactive entertainment industry. Like offline gambling, online gambling bears the risk of addiction and problem gambling, and it has high potential to be misused for money laundering and other financial crimes. Given the 24/7-availablity, high

3 See Statista (2019), "Market Value of online Gambling Worldwide 2017 and 2024", https://www.statista.com/statistics/270728/market-volume-of-online-gaming-worldwide/

${ }^{4}$ See BBC News (12. August 2019) "Gambling companies see huge rise in complaints" https://www.bbc.co.uk/news/business-49284169

5 This is a generalisation: the markets for different forms of gambling (e.g. betting, gaming, lotteries) show different characteristics and are regulated differently. National lotteries, for example, are subject to a monopoly in many EU jurisdictions.

${ }^{6}$ With "offshore" we mean in particular operators located in jurisdictions where they are not subject to (effective) regulation. Generally, however, national gambling laws do not distinguish between unlicensed foreign offers from jurisdictions where there is no regulatory oversight from those where there is regulatory oversight; both are considered "equally" illegal. 
innovation rate, and perceived anonymity online, these risks are exacerbated when players gamble online (Gainsbury et al, 2013; Ford, 2019). While these risks can be controlled more effectively by regulators when it comes to licensed online gambling operators, this is not the case with illegal online gambling. ${ }^{7}$ Operators of illegal online gambling websites are less likely to respect local standards and objectives, such as consumer protection and child-protection standards. Players playing on illegal websites thus risk becoming victims of fraudulent practices, e.g. losing their deposits and being subject to unfair play. The negative effects on consumer protection are worsened by the fact that players are generally not concerned or even unaware whether an online gambling website is legal in their home jurisdiction or not (Gainsbury et al., 2013). There is significant evidence to suggest that underage players are at a significantly higher risk to become problem gamblers, such that online gambling presents a health risk to children (Carran 2018).

Gambling regulators face significant challenges when trying to combat illegal, unlicensed online gambling. Traditional enforcement tools such as administrative and criminal sanctions tend to be ineffective. Frequently, illegal online gambling operators are based outside the jurisdiction of the regulators, and cross-border enforcement of sanctions is very difficult (Hörnle et al., 2019; Hörnle \& Zammit 2010). With traditional regulatory enforcement mechanisms such as fines and sanctions being largely ineffective for enforcing gambling laws against out-of-state operators, gambling regulators thus have started to explore alternative enforcement tools for the online world. These include the blocking of payments to and from illegal gambling operators, blocking online advertising in respect of illegal online gambling, and the blocking of illegal gambling websites (Ibid). In the next section, we further explore the mechanics and practice of the latter.

\section{Website Blocking and Landing Pages}

The practice of website blocking is politically controversial. It is aligned with the debates on state-mandated internet blocking and internet censorship, and questions about its compatibility with freedom of expression and other fundamental rights are regularly raised. In the context of digital copyright and child sex abuse content, for example, internet activists have often managed to create considerable political opposition to legislation proposing internet blocking measures by well-organised internet grass root and media mobilisation (Breindl, 2013; Breindl and Briatte, 2013). In the context of website blocking of illegal online gambling websites, however, there has been little public controversy in Europe

\footnotetext{
${ }^{7}$ A difference can be made between locally unlicensed gambling offers that are licensed and regulated in another jurisdiction, and might thus live up to higher standards than wholly unregulated offers. For the sake of simplicity, we refer to both cases as "illegal gambling" from the perspective of the national gambling regulator. It should be said that other studies take a different approach, e.g. a Dutch study that grouped together Dutch-licensed and EUlicensed offers as "legal" vs "unlicensed" offers referring to offers from the rest of the world. See SEO Economisch Onderzoek (2015), Consumentengedrag online legale en illegale kansspelen, available at http://www.seo.nl/pagina/article/consumentengedrag-online-legaleen-illegale-kansspelen/
} 
compared to blocking to prevent dissemination of child sex abuse or copyright infringing materials (Hörnle et al., 2019, p. 42). ${ }^{8}$

In Europe, the use of website blocking as an enforcement tool has actually gained popularity: It is used by gambling regulators in more than half of all EU/EEA Member States (Ibid, p. 33). ${ }^{9}$ Furthermore, legislators in Finland, Austria and Norway are considering introducing website blocking in their gambling regulation at the time of writing (Ibid, p. 53).

Gambling regulators have essentially two options when it comes to blocking illegal gambling websites. They can block websites on the server's side, i.e. at the place where the website is hosted, thus removing the website from the internet, or on the client's side, i.e. where the player is trying to access the website (internet access blocking). Blocking on the server's side can be done by sending a take-down request to the web hosting provider operating the server. Problems arise, however, when servers are located outside a gambling regulator's jurisdictional reach. Hörnle et al. (2019) show that a majority of servers hosting illegal gambling websites are based in the US (Ibid, p. 52), where hosting providers enjoy strong First Amendment protection. It would thus be difficult to successfully request a take-down of a website hosted in the US based on foreign gambling laws.

This leaves gambling regulators in Europe with client-based website blocking, i.e. blocking at the user end, ${ }^{10}$ as their first choice. There are three client-based blocking technologies: domain name system (DNS) blocking, $\mathrm{IP}^{11}$ blocking, and URL blocking. DNS blocking inhibits the DNS lookup function by disabling the looking up of IP addresses corresponding to a domain name. As this is a very cheap and easy blocking technology, the majority of EU/EEA gambling regulators relies on DNS blocking (Hörnle et al., 2019, p.33 and 45). As the name says, IP blocking measures block an IP address. The problem with IP blocking is that a large number of legal websites can be hosted together with an illegal gambling website at one and the same IP address. IP blocking can thus easily lead to overblocking. Lastly, URL blocking blocks specific URLs, and is thus very precise in its target. At the same time, however, it requires deep packet inspection, ${ }^{12}$ which is costly, and can be difficult to implement if an encrypted connection (https://) is used. In addition, deep packet inspection bears

\footnotetext{
${ }^{8}$ Hörnle et al. (2019) asked in their questionnaire to European gambling regulators whether there had been any controversy regarding the implementation of website blocking against illegal gambling websites. Among all regulators, only the Czech and Dutch regulators indicated that there had been political controversy regarding the introduction of website blocking against illegal online gambling websites.

9 Out of the currently 31 EU- and EEA-Member States, 18 use website blocking as an enforcement tool to regulate online gambling. These are Belgium, Bulgaria, Czech Republic, Cyprus, Denmark, Estonia, France, Greece, Hungary, Italy, Latvia, Lithuania, Poland, Portugal, Romania, Slovakia, Slovenia, and Spain.

${ }^{10}$ Client-based website blocking means that the block is implemented at the user end, i.e. at the location where the blocked internet website is being called up.

${ }^{11}$ An IP address is an address used to identify an internet connection, allowing others to route data packages to devices such as laptops, phones, servers, or IoT devices.

12 Deep packet inspection refers to a data processing technique whereby the packets containing the data sent over a computer network are inspected for their content at certain inspection points. This allows for individual packets to be located, categorized, blocked, and re-routed to a different destination depending on the data they contain.
} 
considerable privacy risks (Fuchs, 2013), as it allows internet service providers and other online intermediaries, for example, to collect and analyse any communication between users or subscribers unless encryption is used.

Gambling regulators across the EU employing website blocking usually follow similar procedures to block illegal gambling websites. First, they discover illegal sites based on their own investigations or on complaints by users or licensed competitors (Hörnle et al., p.35). Secondly, the regulator enters the illegal website's domain on a black list where the domains of illegal gambling websites are collected. In some jurisdictions, gambling regulators need a court order to issue blocking orders against named internet access providers (Ibid, p. 37). ${ }^{13}$ In the majority of EU/EEA jurisdictions, however, regulators can impose website blocking orders through an administrative procedure, without a court order. Website blocking orders are directed either at individual ${ }^{14}$ or all internet access providers in a jurisdiction (Ibid, p.38). ${ }^{15}$ Thirdly, internet access providers block the DNS lookup function for the blacklisted domains.

On the one hand, critics of DNS blocking question its effectiveness. After all, users can simply type in the IP address of the target website in order to circumvent the block. There is surprisingly little research and data on whether players trying to access a blocked gambling website actually engage in such circumvention (Ibid, p. 49). The Estonian gambling regulator, for example, carried out a population survey about gambling behaviour, and one third of respondents reported that they circumvented DNS blocks. The fact that only a very small number of respondents replied that they had engaged in online gambling in the first place, however, made the data sample not statistically representative or generalizable. While it is thus not clear whether there exists a significant amount circumvention at the user end, regulators regularly encounter evasion of DNS blocks at the operator end. Illegal operators continually change their domain names and/or IP addresses to evade website blocks, leading to continuous cat and mouse game for regulators trying to block illegal gambling websites. Moreover, DNS blocking is ineffective in respect of online gambling accessed through mobile apps.

Proponents of website blocking, on the other hand, consider that it is an effective enforcement tool for three main reasons (Ibid, p.43-45). First, website blocking stops at least some users, especially those that are less tech-savvy, from engaging in illegal online gambling. ${ }^{16}$ Second, website blocking allows regulators to redirect users trying to access a blocked website to a landing page, which gives regulators the possibility to analyse traffic data (Ibid, p.45). Traffic analysis tells regulators where a user redirected to the landing page came from (e.g. from a search engine), the

\footnotetext{
13 Jurisdictions in which regulators need a court order to impose blocking measures are Slovakia, France, Denmark, Lithuania, Slovenia.

${ }^{14}$ Slovenia, Slovakia, Portugal, France.

${ }^{15}$ This can cause issues for internet access providers operating in several territories or border regions

${ }^{16}$ Some evidence in this regards comes from the French online gambling regulator reporting that some players complained to it for not being able to play on blocked gambling websites, see EI France.
} 
keywords used for searching, and to which page the user went after viewing the landing page. It also tells regulators how many users are trying to access illegal gambling websites overall. Thirdly, and most importantly, the landing page itself is an effective communication tool for regulators to warn consumers directly that they are trying to access an illegal gambling website and of the risks associated with illegal gambling. This is especially important for consumers that are unaware, but intend and prefer to play on legal, locally licensed gambling websites (Ibid, p.43). The landing page is thus an important tool for consumer information and protection, and it is capable of channelling demand to locally licensed and supervised online gambling offers.

In this contribution, we focus exclusively on the third aspect: landing pages as a communication tool between regulators and players. We explore how effective design of landing pages could possibly further the objectives of gambling regulation.

Landing pages can fulfil a range of purposes. First, it is considered good practice in internet filtering that users are informed that they have been blocked from accessing a website and the reasons for the block (Burnett \& Feamster, 2013; Zittrain \& Palfrey, 2009). A landing page can fulfil this function very easily by simply displaying a text. Secondly, a landing page can inform and warn users about the consequences of playing on illegal gambling websites. In the jurisdictions in which players can be criminally prosecuted for engaging in illegal gambling, players can also be informed that they might commit a criminal offence by playing on the blocked site. ${ }^{17}$ In addition, landing pages allow embedding of a link to locally licensed operators' gambling websites, which makes it easier for users to access legal gambling websites and channels demand to legal offers. Finally, the landing page also allows for the inclusion of a feedback function through which users can communicate and engage with the regulator.

All these positive effects, however, can only be achieved if landing pages are designed in a user-friendly manner. After all, regulators communicate with users that are looking for entertainment and the thrill of 'betting a buck', or, even worse, are trying to satisfy an addiction. Such users are unlikely to read and engage with a landing page that has no visual stimuli and only a wall of legal text and may appear dull and boring, or simply irrelevant to the user groups in question. In the next section, we present some examples of landing pages used by European gambling regulators and engage with them critically.

\section{Landing Page Examples}

In this section, we present and discuss the landing pages from the Estonian, French, Spanish, and Polish gambling regulators. We have chosen this sample to show a range of options in landing page design that various regulators have chosen, from almost playful (Spain) to very neutral (Estonia), from providing information in a very concise manner (Estonia, Spain) to an extremely wordy manner (France, Poland).

${ }^{17}$ This is the case, for example, in Poland. 
The sample chosen also shows that certain design components are universal (e.g. providing information about the legal basis for website blocking), whereas others are not. Some of these differences in landing page design components are rooted in different regulatory approaches to online gambling. In France and Spain, for example, the blacklists of blocked online gambling websites are not public, but they are public in Estonia and Poland (Hörnle et al. 2019, p. 39). While the French and Spanish landing pages thus do not include a link to the blacklist, the Polish and Estonian landing pages include a link.

Another regulatory difference that is reflected in landing page design is whether players can be sanctioned for playing on illegal, unauthorized landing pages in the country in question. In Europe, there are only very few states that impose sanctions on players. ${ }^{18}$ Poland is one of them, and the landing page thus includes information regarding the legal consequences if players decide to circumvent the website block and play on illegal, locally unauthorised gambling websites.

\subsection{Estonia}

The regulation of gambling in Estonia is carried out jointly between the Ministry of Finance and the Tax and Customs Board. It is the latter that makes the landing page for blocked gambling websites available. ${ }^{19}$

The landing page is white and grey and displays a small amount of text in black. The overall visual impression is very neutral due to the plain design chosen by the regulator. While it does not contain any attractive, animating details, it has the benefit of being simple, avoiding long passages of text and with a clear, informative heading "Access is blocked". The font is legible and clear.

In terms of content, the landing page explains that the website has been blocked on the basis of the Estonian Gambling Act, and that it is the task of the Tax and Customs Board to prevent all forms of illegal online gambling. In addition, the page contains a link to the list of blocked gambling sites (blacklist) and a link to operators that have a gambling license in Estonia (whitelist). The name, website and email address of the regulatory authority is mentioned at the bottom of the site. The landing page is available in three languages, Estonian, English, and Russian, reflecting the main languages spoken in the country.

\footnotetext{
${ }^{18}$ These include Germany, Poland and Lithuania. See Hörnle et al. 2019 (p. 124).

${ }^{19}$ Estonian Ministry of Finance, link to landing page: https://www.emta.ee/et/juurdepaasblokeeritud
} 

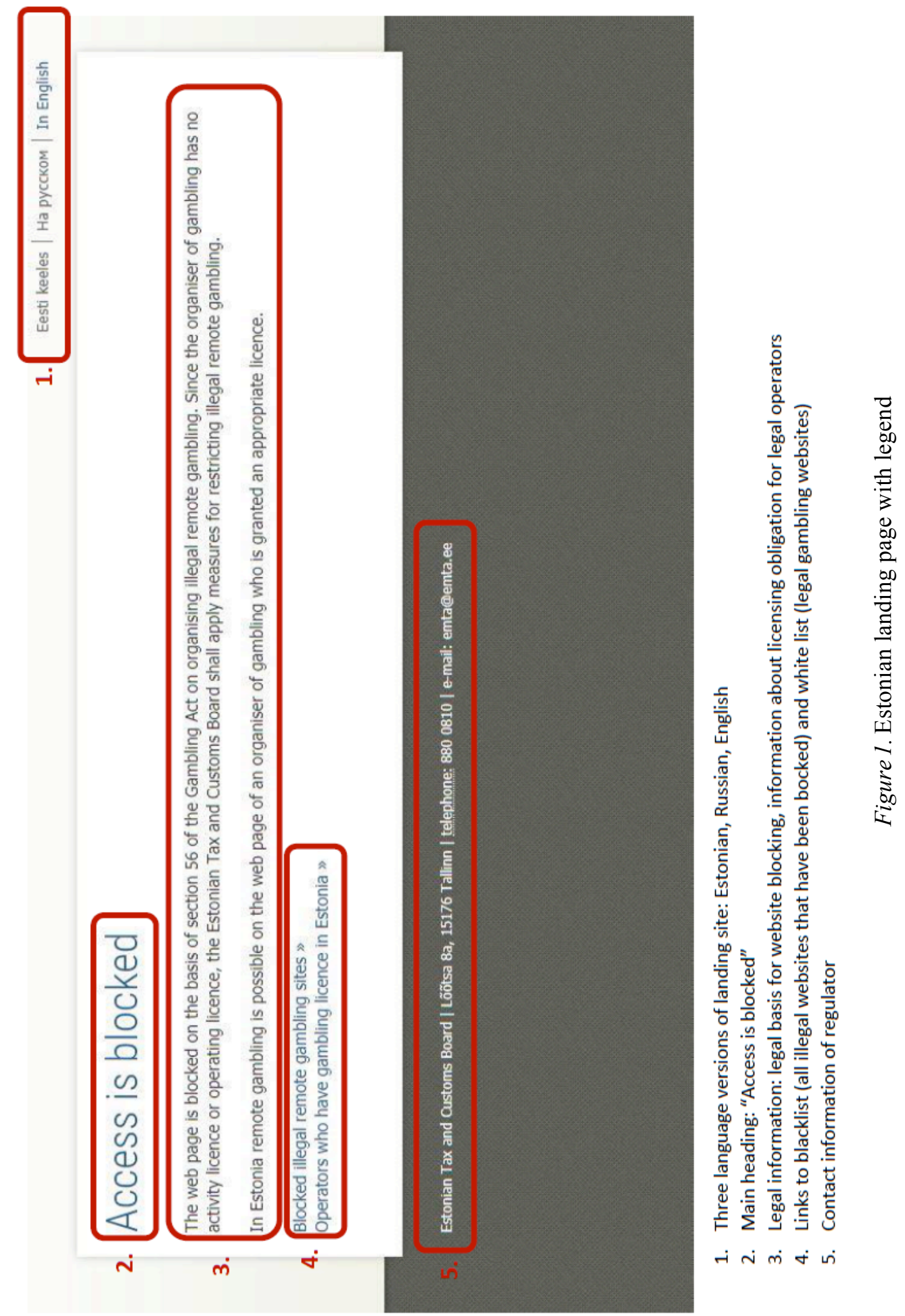


\subsection{France}

France has a specialized regulatory authority for online gambling, the Autorité de Régulation des Jeux en Ligne. This authority also provides the landing page. ${ }^{20}$

The overall visual impression of the French landing page is different from the Estonian landing page. While the main colours are still white and grey, and the text is black, the regulator's logo heads the page in red, blue, and violet colours. The website displays a relatively large amount of text in very small font. Only the heading of "site inaccessible" and the information that the website has been blocked by a court order are displayed in larger font and in bold.

In terms of content, the site contains an explanation that it has been blocked due to a court order for the violation of the French Online Gambling Act. The text goes on to explain that the blocking is intended to inhibit access to websites which might host potentially dangerous games. It explains that contrary to licensed operators, illegal operators have no obligation to protect vulnerable players, to guarantee players' deposits, to protect personal data, or to prevent problem gambling. In addition, the text explains that offering illegal online gambling is a criminal offence in France and can be punished by up to three years imprisonment or a large fine. The authority also invites users to get in touch regarding the landing page and blocked website (user engagement). Lastly, there is a link to "Evalujeu", a website offered by the French regulator with information on online gambling and a tool that helps evaluate whether one's gambling behaviour amounts to problem gambling.

${ }^{20}$ ARJEL, IP address of landing page http://46.183.50.41/ 


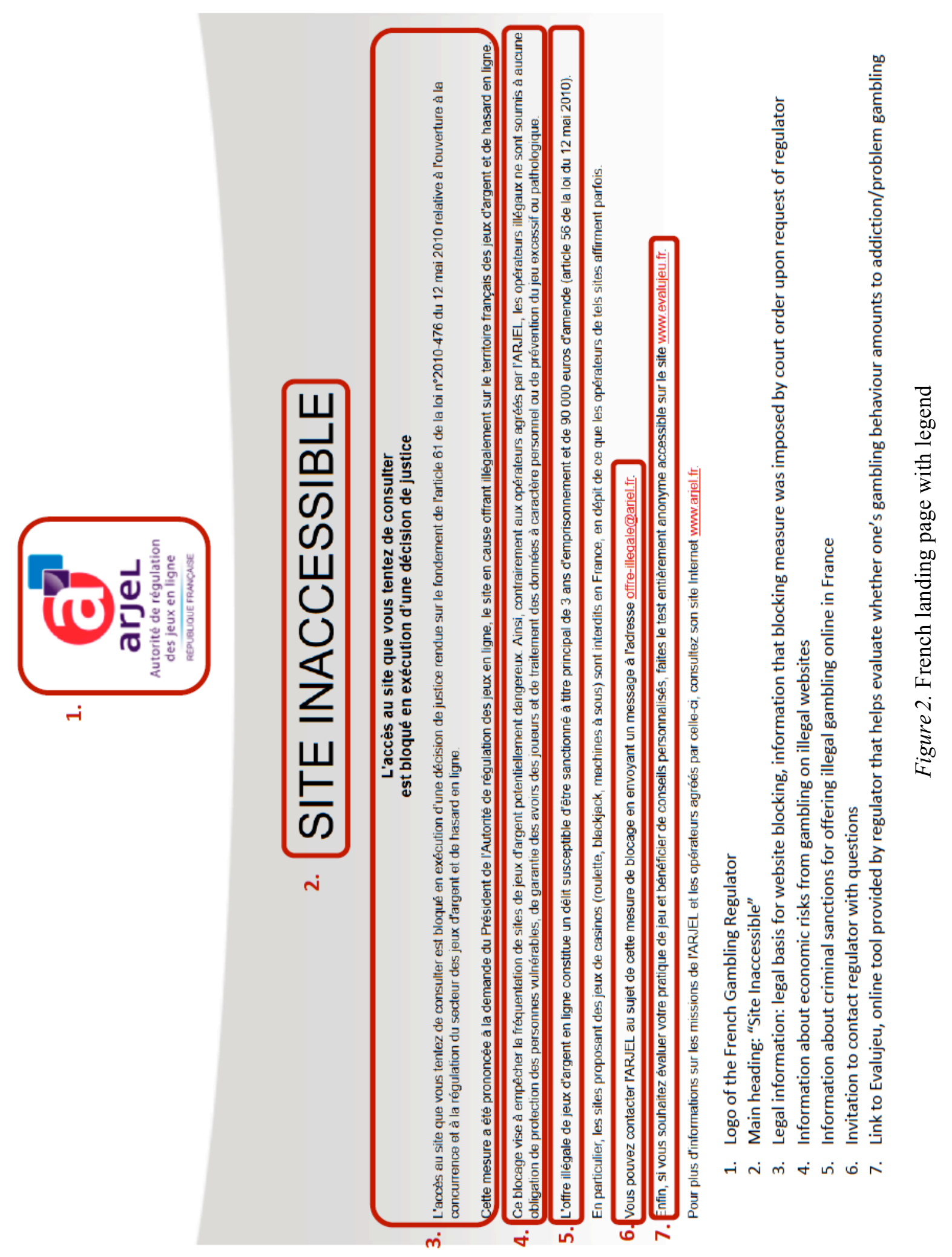




\subsection{Spain}

In Spain, the competence to regulate gambling is split between the Autonomous Regions and the Central Government. Online gambling is mainly regulated at central level by a unit of the Ministry of Finance, the Directorate General of Gambling Regulation (Dirección General de la Ordenación del Juego - DGOJ). The DGOJ provides the landing page for blocked gambling websites in Spain. ${ }^{21}$

The overall visual impression of the Spanish website is again different from its Estonian and French counter parts. The website has a white background and displays a text in dark yellow and grey, using a contrasting and colourful design. It also displays a variety of logos (rather than text) that can be clicked to be forwarded to another page.

Content wise, a sentence heads the page stating that the user is trying to access a website of a gambling operator without a license. Below this sentence is the title of the Spanish Gambling Act, which can be clicked and forwards the user to the legislature's website containing the whole Act. Below, there is the trust mark "juego seguro" (safe play) that is displayed by licensed operators. This is a straightforward message linking licensed play with safety. ${ }^{22}$ The trust mark is a clickable icon that leads to the regulator's website about safe play. The website also contains a link to the whitelist of licensed operators, which may help to channel demand. At the bottom of the page, there is yet a further logo of "jugar bien" (play well), which is clickable and leads to a website offered by the regulators with information about responsible gambling and problem gambling. Lastly, the symbols of the Spanish state are displayed with the name of the responsible Ministry and Unit for regulating online gambling.

${ }^{21}$ IP address of landing page: $h$ ttp://192.187.20.203

${ }^{22}$ Whether this is factually true or not is not at issue here. 

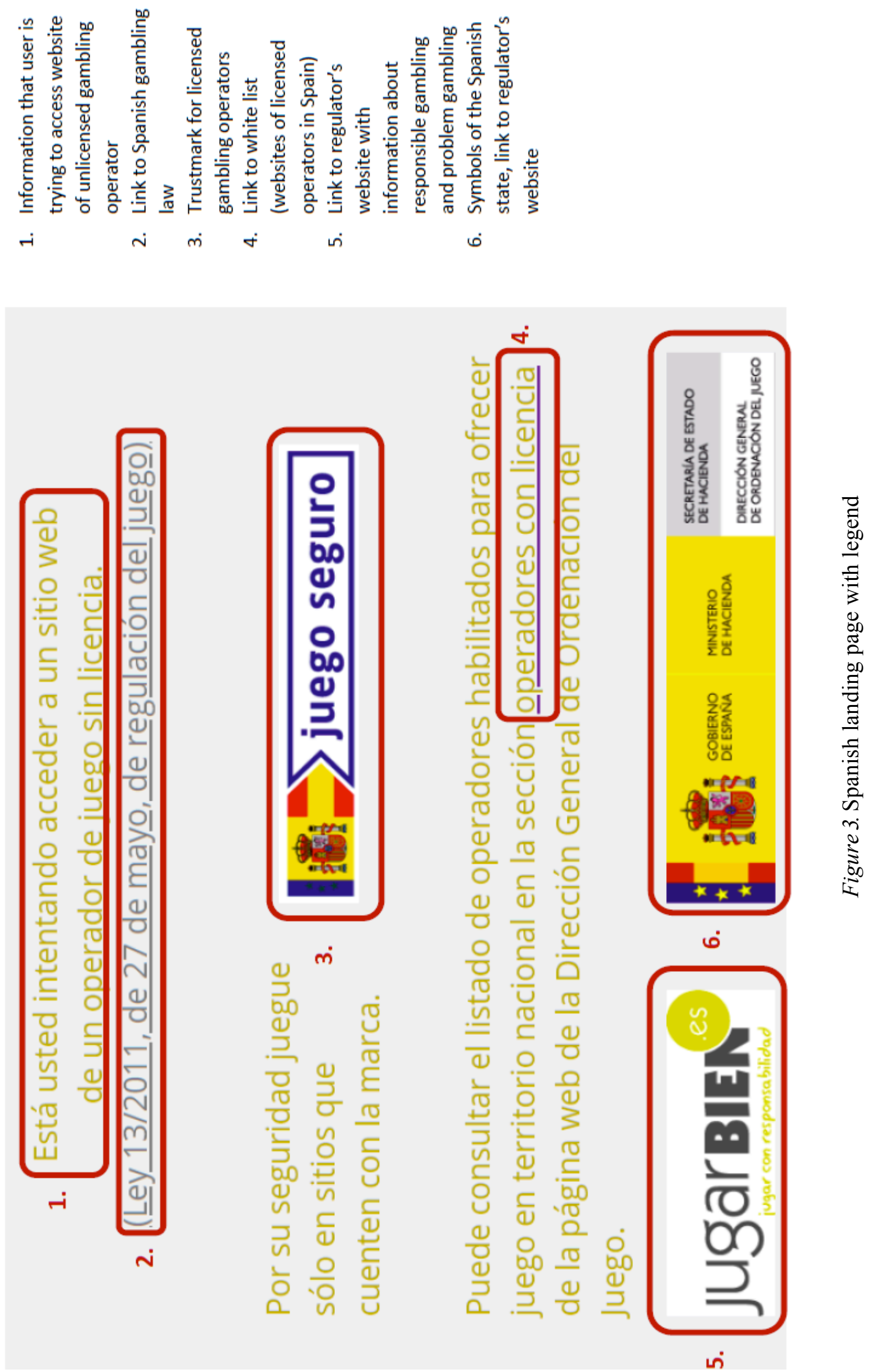


\subsection{Poland}

In Poland, competences regarding gambling regulation are split between various government agencies. The Ministry of Finance is responsible for gambling policy, whereas the National Revenue Service, i.e. the tax authority, is responsible for the enforcement of gambling regulation. The Polish landing page is provided by the Ministry of Finance.

The Polish landing page is embedded in the overall homepage of the Ministry of Finance. The main colours of the landing page are white and tones of grey, while there are some orange and red highlights in the overall design of the Ministry of Finance's homepage. The landing page displays a very large amount of text over several paragraphs in small font. Only the first two lines of text are in bold and contain the message "Warning!" and that the site has been blocked because it contains illegal gambling offers.

In terms of content, the landing page provides information about the legal basis upon which the block has been imposed and a link to the blacklist of blocked gambling websites. Furthermore, it provides information about the administrative and criminal fiscal sanctions for players that engage in locally unauthorised or foreign online gambling. In the last paragraph, the text explains that there are legal offers provided by the state monopolist and by license holders. The text then provides a link to the whitelist of locally authorised online gambling operators. 


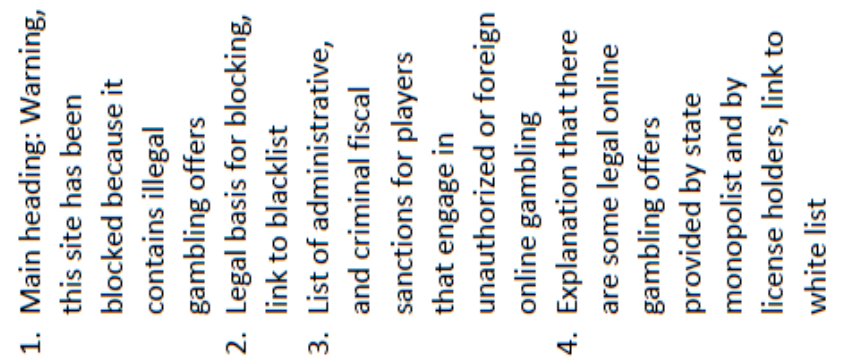

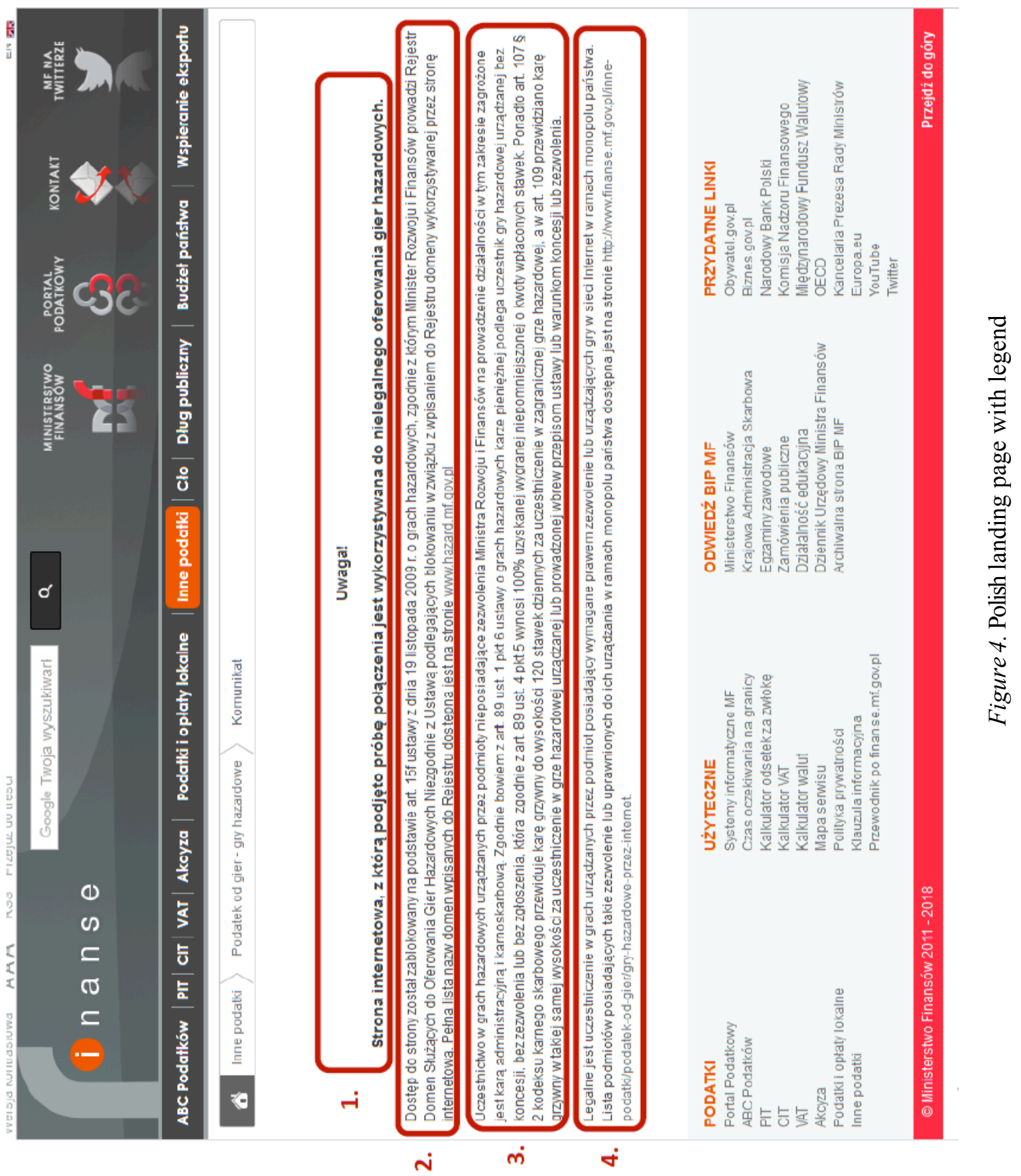




\subsection{Reflections about the landing page examples}

The four landing pages above exemplify a variety of different approaches in design. While the pages of the Estonian and Spanish regulators include very little text, in clear and legible font, the French and Polish websites contain a wall of text in very small font, with lots of information. While a lot of text does not necessarily mean that the text is written in legalese as exemplified by the French landing page, this is the case in the Polish example, which includes a lot of technical information on, among other legal issues, tax legislation. Such legalistic language and references to legislation, as well as long passages of text may pose problems to the effectiveness of the landing page as communication tool. Many users might find such landing page impenetrable and off-putting.

While the Spanish and Estonian landing pages score well on legibility and clarity, they do not have immediate information for users as to the economic and legal risks they might be facing when playing on illegal websites. The French and Polish landing pages are better in this respect, but if their design leads to these pages not being read in the first place, no effect on player behaviour is to be expected. The Spanish website includes a button linking to a website that allows players to read about responsible gambling (button jugar bien) and a button linking to a website that explains why locally licensed online gambling offers are to be preferred (button juego seguro). It is not clear, however, whether users would expect such information behind these buttons and what the likelihood of them clicking these buttons is. This could be assessed via behavioural experiments. ${ }^{23}$

In light of the goal of protecting consumers and channelling demand to legal offers, some elements of the examples intuitively seem to be a good idea. These include:

- several language versions of the landing page (Estonia) to ensure that all language groups in a country are captured,

- a link to the whitelist (Spain, Estonia and Poland) in order to channel demand,

- a link to the text of the applicable legislation (Spain),

- a warning regarding the economic (France) and legal (Poland) risks from playing on illegal sites,

- self-help tools for at-risk or problem gamblers helping them to assess their gambling (France), and

- providing contact information and encouraging gamblers to communicate and engage with regulators (France).

It is difficult to judge whether each of these features is effective and which combination of features and design actually leads to persuading players not to play on illegal gambling sites and channel their demand to locally licensed offers instead. ${ }^{24}$ This is where insights from legal design paired with behavioural experiments could truly help regulators identify features

\footnotetext{
${ }^{23}$ See discussion in Section 5 below

${ }^{24}$ To our knowledge, there is no study on this issue to date.
} 
and designs that are effective in terms of communication and in terms of influencing players' behaviour.

\section{Improving Landing Pages with Insights from Legal Design}

The design of legal texts in a user-friendly fashion has been explored in other contexts in previous research studies, for example when it comes to contract design (Haapio and Passera, 2018) and to privacy notices (Haapio et al., 2018). The design approach to legal texts takes the user as its focus, and adapts and redesigns legal texts to suit her needs. It is not only the lawyer who should understand the text, but the consumer, the builder, the manager, etc. The design approach also includes classifying legal information into easily understandable categories. ${ }^{25}$

We can think of landing pages as another example of a legal text addressed to a (non-legally qualified) user, which could benefit from insights from effective legal design. There are various options when it comes to designing or redesigning landing pages to make them more effective as a communication tool. Options range from improving the website visually with information and interactive design, to improving the content, to using plain language and pictorial designs (such as logos). In the following, we discuss the use of three techniques that could be used in order to improve and test the effectiveness of landing pages: design patterns, online behavioural experiments, and eye tracking.

\subsection{Design Patterns}

The concept of patterns to communicate re-usable solutions for a category of reoccurring problems comes from architecture (Alexander et al. 1977). The idea of design patterns has spread to many other disciplines, from computer science to information systems (Rossi et al., 2019), and more recently also to law and legal design (Haapio \& Hagan 2016). The development of design patterns is very much user-focused; the characteristics of the addressee of a legal text determine the shape and content of the patterns, which can help to build a well-designed legal text (Rossi et al. 2019).

In the context of contracting, Haapio \& Hagan (2016) define design patterns as "reusable models of a solution to a commonly occurring problem"; design patterns are thus first and foremost problem-solving tools. The use of patterns should make communication more productive and efficient between two parties. Patterns should offer a common, standardized language that is easier to understand than the often convoluted, impenetrable 'legalese' (Ibid).

Legal design patterns can also be applied to privacy notices, as discussed by Haapio et al.(2018). The authors even created their online design pattern

\footnotetext{
${ }^{25}$ See for example the project "Terms of Service Didn't Read" https://tosdr.org/
} 
library for privacy notices, ${ }^{26}$ where they show how, for example, privacy icons and multi-layering of privacy notices can help users understand privacy notices easier and faster. This, in turn, allows users to compare and evaluate various privacy policies before deciding, for example, whether to subscribe to an online service. A similar approach was taken by the project "Terms of Service Didn't Read".

Privacy Notices and Terms of Service provide a different type of content compared to landing pages used by gambling regulators. Nonetheless, the two types of legal information are intended, at least in part, to enable consumers and users to make informed choices and understand the implications of complex legal relationships (such as the risks of privacy invasive technologies or gambling on unlicensed, as opposed to regulated and supervised gambling offers). Privacy notices inform users about the consequences from using a service for the user's privacy, and landing pages inform about the consequences of engaging in illegal gambling.

One of the generally raised critiques of privacy notices is that they are so complex and long that users do not bother reading them and simply click "agree". When this is the case, the privacy notice fails to perform its intended function of informing and empowering the user/consumer. Similarly, a landing page that is not read or does not engage a player will not yield its intended benefits of encouraging users to weigh up the risks. While a player might be dissuaded by a simple 'stop' or 'warning' message, an informative landing page could educate players about illegal gambling and influence their behaviour in a longer-lasting way.

Rossi et al. (2019) have identified hurdles that prevent consumers from reading and engaging with privacy notices. These include illegibility due to small print, language complexity, vagueness of terms, wall of text, excessive length, lack of audience-tailoring, wrong timing, lack of familiarity, inaccessibility for visually impaired users, scattered information, excessive number of "legals", and difficult comparability. Given that the information and the text on landing pages is significantly shorter than privacy notices, hurdles such as excessive length, scattered information, and excessive number of "legals" are less of an issue. Furthermore, comparability is not important in the case of landing pages, since a user is not choosing from a variety of landing pages, but there is only one landing page provided by the regulator. In addition, landing pages are well-timed, because the consumer encounters them just before taking the decision whether to engage in illegal online gambling.

There are, however, some of the hurdles with privacy notices which equally could be considered as relevant to the hurdles for players confronting landing pages. These include illegibility, language complexity, vagueness of terms, walls of text, lack of familiarity with legal language, and lack of audience-tailoring. The French and Polish landing pages, for example, are written in very small font and form a wall of text. The Polish landing page contains a lot of technical legal language. Furthermore, all pages do not seem to be designed to engage the average player that is looking for

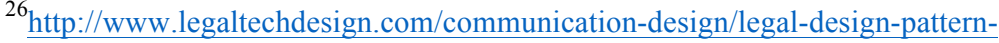
libraries/privacy-design-pattern-library/

${ }^{27}$ https://tosdr.org/
} 
gambling offers online with the content of the page.

Rossi et al. (2019) then suggest information design patterns to overcome these hurdles. Leaving aside those patterns that address excessive length and information overload specific to privacy notices (order and labels, table of content, timelines, reading time estimation, progress mechanism), there are several patterns that could be applied to landing pages, too. These include, for example, a FAQs section or a question-answer chatbot that could give information about the law that led to the blocking of a website or the consequences of playing on illegal gambling websites.

When it comes to illegibility of small print, for example, the pattern of using a larger and more readable font could be used. If regulators decide to include more information on the landing pages, and the text becomes too long to fit the page in larger font, the text could be layered, for example by showing only part of the text or keywords, while the remainder can be seen by clicking on the displayed text. This would also avoid "walls of text" that look impenetrable and put the reader off. Again, the French and Polish landing pages present examples of illegible small print and a wall of text that could be improved by using these patterns. Lengthy text should additionally be shortened and simplified, and replaced by illustrations and pictures wherever sensible and possible.

Problems with language complexity, vagueness or lack of familiarity with legal language could be remedied by using plain language (Rossi et al., 2019; Adler, 2012). In addition to using plain language, gambling regulators might even consider using child- or rather youth-friendly language (Rossi et al., 2019), given that children and youth are a group of persons that gambling regulation seeks to protect especially (Hörnle et al., 2019, p.143). Including a small video on the website explaining the risks of illegal gambling, or with a testimony from a problem gambler, might be an even better idea to transmit the message to (young) users (Rossi et al., 2019).

When it comes to the overall visual impression and structuring of information on landing pages for users with a relatively short attention span, the use of icons in combination with a structured text (use of various fonts, colours, and data tags) could be a promising idea to test. These would make it easier for users to grasp the range of different types of information on a website. In the context of privacy notices, for example, it is suggested that icons can help readers locate relevant information more quickly. There is extensive work on privacy icons that could possibly help develop icons for landing pages. ${ }^{28}$

Lastly, gamifying the landing page or using cartoons could be an idea to explore for landing pages. After all, a regulator might be able to reach players looking for online entertainment in a more effective way if they communicate their message through a "fun" medium as a cartoon or game.

Developing design patterns for landing pages would mean to create a common framework that any regulator could take as inspiration to design

\footnotetext{
${ }^{28}$ See for a list of sources http://www.legaltechdesign.com/communication-design/portfolioitem/privacy-icons/
} 
their own landing page. In the future, these design patters could potentially be taken beyond the area of gambling to other forms of websites with illegal content that are blocked by national authorities, such as hard-core pornography, pirated content, and child sex abuse content. The respective landing pages would need to be adapted to each context.

Moreover, in addition to a "rational" assessment of legal design, in other words testing the effectiveness of information communication, the "emotional" impact of such communication should be assessed. Particularly in the field of gambling, which involves impulsive behaviours, the emotive appeal and impact of landing pages needs to be factored into communication patterns. It is thus important to acknowledge that decisionmaking is not only based on rational information, but includes emotional and subliminal factors which need to be taken into account (and which the advertising and online gambling industry is well-aware of). It is here, too that behavioural experiments may also offer important insights.

\subsection{Behavioural experiments}

In order to identify which design pattern for landing pages would be particularly effective to steer away players from playing on illegal websites, behavioural experiments would be necessary. Behavioural experiments would provide the means to obtain empirical evidence about the effectiveness of a specific design pattern for landing pages.

Websites offer a particularly well suited environment for behavioural experiments. This is in particular the case, when the experiment aims at helping to assess whether changes in the interface influence consumer behaviour. Online experiments allow the collection of large data sets at a very low cost and with relative ease and a lot of open-source software is available for conducting them (Reips, 2002; Birnbaum, 2004).

Drawing from website design experiments within marketing (e.g. De Angeli et al. 2006, Cyr et al. 2009), behavioural experiments with landing pages could involve, for example, displaying two different designs of a landing page to two different test groups in order to find out which group stays longer on the website, engages more with its interactive features, etc. Such experiments could even shed some light on whether landing page design could influence whether a player attempts to circumvent the landing page or not. This would allow for judging the relative effectiveness of different landing page designs. The concrete set up of such behavioural experiments is a subject for future research. ${ }^{29}$

\subsection{Eye tracking}

The use of behavioural experiments could be taken further from the internet to the lab to achieve results that provide even more insights about the reaction of test persons to the design of the landing page. Eye tracking is a technique used in marketing and consumer research to assess consumers' visual engagement with a marketing message and understand their

\footnotetext{
${ }^{29}$ We are beginning to set up such research in collaboration with Copenhagen Business
} School's Marketing Department. 
cognitive engagement. It involves the use of experimental research designs in which the eye movement of test persons when facing a marketing message is measured through the use of cameras. These can be incorporated in glasses for tests where person looks at a physical representation of a marketing message, or built into a computer screen or monitor for testing a person's gaze pattern when looking at a digital message. Software then processes the video images of the eye movement and can tell researchers what the test person looked at, for how long, whether the eyes were wandering around very much or were fixed on one point, etc. This allows for inferences about, for example, the elements on which the test person focused her attention, or whether she was completely distracted or lost when looking at the message, to be drawn. Subsequently, the eye-track test could be supplemented with interviews about how the test persons perceived the marketing message and how it would influence their behaviour.

When testing the effectiveness of landing pages on users, eye-tracking experiments could help to obtain even deeper insights than with mere online behavioural experiments about which landing page design is effective. ${ }^{30}$ Variables such as the amount of text, the font type, size, colours, background, icons, and the type of information displayed could individually be measured as to their effect on the user. The concrete set up and carrying out of these experiments would be the object of future research together with experts in the field of neuromarketing.

\section{Conclusion}

The combination of blocking illegal gambling websites and an informative and well-designed landing page can constitute an effective enforcement and player protection tool for gambling regulators. In order to exploit the possible benefits of landing pages fully, however, landing pages need to be designed well and their design needs to be tested in behavioural experiments.

This article lays out the regulatory framework for the blocking of illegal gambling websites and provides a range of four examples of landing pages currently used by European gambling regulators. We take an intuitive approach to analysing these examples by pointing out their features and the likely effect of some of these features on users.

We then examine existing literature on legal design, and in particular regarding the use of legal design patterns. We especially look for inspiration in the ideal, user-friendly design features of privacy policies to enable internet users to make informed choices with the help of clearer communication of privacy policies. By analogy, our conclusion is that the communication of information on landing pages is like-wise about decision making in the sense that one of their purposes is to aid gamblers in making a personal risk assessment and protect them from the risks inherent in (some) unlicensed, illegal online gambling. While privacy policies should

\footnotetext{
${ }^{30}$ There has been research before in the field of gambling advertising and its effect on problem gamblers using eye tracking, see Binde, P. Exploring the Impact of Gambling Advertising: An Interview Study of Problem Gamblers,. Int J Ment Health Addiction (2009) $7: 541-554$.
} 
warn users about the risks of privacy invasion, landing pages should warn users about the risks of (some) unlicensed online gambling. ${ }^{31}$

Landing pages, however, may have additional "warning functions", for example by linking to relevant resources that help individual gamblers to assess their own playing patterns as to potentially problematic or addictive behaviours. Furthermore, landing pages can involve user-engagement and communication (such as feedback and complaints) with the regulator.

We argue that the effectiveness of landing pages for these different types of communication and information flows should be examined further through empirical research, given recent concerns about unlicensed gambling and consumer protection, and given the fact that landing pages as a feature of website blocking are an important tool in the European gambling regulators' toolkit. Finally, we sketch some of the research methods to be used in gaining further insight into the effectiveness of landing pages and proposed a behavioural study and eye-tracking, leaning on methodologies developed in the context of marketing research.

\section{Acknowledgements}

We thank Stefania Passera who kindly gave us a first idea about how insights from legal design could be applied to landing pages in the fall of 2018, and we thank Jesper Clement for giving us an overview about how eye-tracking experiments could be used to test the effectiveness of different designs of landing pages. We also thank the European Commission for funding the EU Study "Evaluation of regulatory tools for enforcing online gambling rules and channelling demand towards controlled offers"

\section{References}

Adler, M. (2012). The Plain Language Movement, in Solan, L.M. and Tiersma, P.M. (eds), "The Oxford handbook of Language and Law", Oxford University Press, New York

Alexander, C. (1977), A Pattern Language, Towns, Buildings, Construction, Oxford University Press, New York, NY.

Birnbaum, M.H. (2004), Human Research and Data Collection via the Internet, Annual Review of Psychology, Vol. 55, p. 803-832

Breindl, Y. (2013), Discourse Networks on State-Mandated Access Blocking in Germany and France, info, Vol. 15, No. 6, p. 42-62

Breindly, Y. and Briatte, F. (2013), A Digital Protest Skills and Online Activism Against Copyright Reform in France and the European Union, Policy and Internet, Vol. 5, No. 1, p. 27-55-

Burnett, S. and Feamster, N. (2013), Making Sense of Internet Censorship: A New Frontier for Internet Measurement, ACM SIGCOMM Computer Communication Review, Vol. 43, No. 3, p. 84-89

Carran, M. (2018), Gambling Regulation and Vulnerability, Edward Elgar, Cheltenham

\footnotetext{
${ }^{31}$ Not all unlicensed online gambling sites pose the same risks, though (see also fn 7), but this is not the topic of this article, but something to be acknowledged in the design of our research study.
} 
Cyr, D. et al. (2010), Colour Appeal in Website Design Within and Across Cultures: A Multi-Method Evaluation, International Journal of HumanComputer Studies, Vol. 68 (1-2), 1-21

De Angeli, A. et al. (2006), Interaction, Usability and Aesthetics: What Influences Users' Preferences, Proceedings of the $6^{\text {th }}$ conference on Designing Interactive Systems.

Ford, J. (2019), The Troubling Legacy of Britain's Gambling Experiment, Financial Times, 19 July

Fuchs, C. (2013) Societal and Ideological Impacts of Deep Packet Inspection Internet Surveillance, Information, Communication \& Society, Vol. 16, No. 8, p. $1328-1359$

Haapio, H. and Hagan, M. (2016), Design Patterns for Privacy, in Schweighofer, E. et al. (eds), "Networks, Proceedigns of the $19^{\text {th }}$ International Legal Informatics Symposium IRIS 2016, Österreichische Computer Gesellschaft OCG Wien 2018, p. 381-388, also available at https://papers.ssrn.com/sol3/papers.cfm?abstract id=2747280 (accessed 27 September 2019)

Haapio, H. et al (2018), Design Patterns for Privacy, In Erich Schweighofer et al. (Eds.), Data Protection / LegalTech. Proceedings of the 21th International Legal Informatics Symposium IRIS 2018. Editions Weblaw, Bern 2018, pp. 445-450 and in Jusletter IT, 22 February 2018.

Hörnle, J. and Zammit, B. (2010), Cross-border Online Gambling Law and Policy, Edward Elgar, Cheltenham

Hörnle et al (2019), Evaluation of Regulatory Tools for Enforcing Online Gambling Rules and Channelling Demand towards Controlled Offers, Publications Office of the European Union, Luxembourg, available at https://publications.europa.eu/en/publication-detail/-/publication/6bac $835 \mathrm{f}-$ 2442-11e9-8d04-01aa75ed71a1/language-en (accessed 27 September 2019) Reips, U. (2002), Standards for Internet-Based Experimenting, Experimental Psychology, Vol.49, No. 4, p. 243-256

Rossi, A. et al. (2019), Legal Design Patterns Towards a New Language for Legal Information Design, JUSLetter IT "Internet of Things - Digital Edition of Proceedings of the 22nd International Legal Informatics Symposium 2019

Zittrain, J. and Palfrey, J. (2009), Internet Filtering: The Politics and Mechansims of Control, in Deibert, R. et al. (eds), "Access Denied - The Practice and Policy of Internet Filtering", MIT Press, Cambridge, Mass. pp. 29-56. 